\section{MIDDLE CLASS IN THE NEW SOCIAL STRUCTURE OF KAZAKHSTANI SOCIETY}

\section{Introduction}

Today the problem of formation of middle class in the modern Kazakhstani society is in the spotlight of politicians, and scientists (sociologists, political scientists and economists), which is associated with the need to evaluate the effectiveness of the transformation processes. However, as in Kazakhstani science there is no clear idea of criteria for allocation the middle class, and thus questions about its presence in the social space, its size and composition, education and life strategies remain discussible.

Therefore, giving a specific definition of borders of the middle class or describing its representatives is very difficult process. There are many different approaches for determining the middle class. It is possible to try defining a middle class by income, education level or socio-professional categories. But, at the same time, these approaches separately are not satisfactory to explain such complex social totality as the middle class. It seems logical to use a complex of certain criteria related to ability of the middle class to normally perform associated functions, including stabilization of the sociopolitical situation, the role of the main economic "donor", including function of a "provider" of highly skilled workforce and major taxpayer, as well as a function of dissemination of new socioeconomic and socio-cultural practices, and a carrier of the national culture and values [1].

Main part. Usually a combination of a set of objective and subjective criteria is used. Objective criterion is based on a set of attributes that do not depend on the opinion of the individual. Besides such attributes as the characteristics of the socioprofessional status (non-physical nature of the work) and the level of well-being (indicators of permanent income, average monthly per capita income, the amount of accumulated savings, the level of property provision or the amount of consumer durables), a level of education is included here. Subjective criterion is based on the "selfidentification" - the opinion of society members regarding their affiliation with a social layer. This approach covers at least the most basic characteristics of the middle class and acts not only as a purely descriptive approach, but also considers such important criteria as self-identification of a person [2]. 
Criteria of determination of middle class: Most of experts agree that the material well-being is an important indicator for inclusion to the middle class; family must have a certain level of stable earnings to be included in the middle class. Level of these earnings in large cities of Kazakhstan should be between 500 to 1500 U.S. dollars per person, thus being distributed into different layers inside the middle class.

Expert 1: "Families, where per capita income is about $\$ 1500$ and the lower part of the middle class is defined by per capita income of $\$ 500$. These boundaries are very fluid; they are specific to each Kazakhstan region or one or another group of cities. For the middle class, not only income is important, but also a lifestyle, a feeling is very important".

Experts are also unanimous about the existence of integral classifications, when the combination of characteristics such as income, education, housing, professional status and etc. allows individuals to refer to a certain class.

Expert 2: "Income, education, social status. This is the general criteria for many countries".

Expert 3: "Criteria for the middle class: ... higher education, the presence of housing, and the constant professional work, the average steady income."

Within the approach following criteria for determining the middle class were selected:

- The level of well-being, formed by the presence of permanent income, average monthly per capita income indicators and other indirect indicators (number of existing consumer durables the amount of savings). The level of well-being in any economic conditions is determined by current income combined with the whole complex of tangible assets. In this respect, the use of a wide range of material and property indicators reduces the likelihood of errors.

It is a permanent stable income gives the opportunity to individuals to feel stability and allows planning the future. Also, to assign an individual to the middle-class indicators of monthly income per family member for the last 6 months should constitute more than 5.3 living wages for Almaty (according to the law of Republic of Kazakhstan "On republican budget for 2013-2015"); this is more than 100 thousand KZT per month per family member. Experts stressed that the important thing is not the size of this income but constancy, which guarantees the preservation of property and social status. Also it is taken into consideration a presence of indirect signs of well-being: the amount of savings, self-evaluation of family material situation, and the availability of consumer durables. One of the important features of the middle class is that the members of this class have an opportunity to accumulate certain funds, and they, unlike the poor, have a plan on how to use the accumulated funds. However, it should also be noted that the middle class may have limitations, and they cannot afford expensive luxuries, unlike the rich. If at least one of these criteria is present an individual is included to the middle class in terms of welfare.

- Characteristics of the socio-professional status (the criterion of non-physical nature of work). In this approach a non-physical nature of the work is used as a criterion for getting into the middle class. Socioprofessional status in a class society is a marker of certain structural positions. This allows separating the structural position of the middle class from the position of lower class. Fluctuations of professional status are allowed, but the basic income should be the result of professional activity, but secondary sources of income of the middle class may vary.

First of all, intellectual labor representatives requiring specialized higher education should be counted among middle class. Also, the fact that a manager profession has one of the leading positions is indicative. This concept includes a number of management and other functions, and is an indicator of formation of middle class in the western tradition. Naturally, the self-employed people and entrepreneurs are also included to middle class on the socio-professional status. This part constitutes traditionally allocated the old middle class, which has ownership of the means of production, but which does not use a hired labor on a large scale.

- Level of education (presence of at least a basic higher education (bachelor degree). In order to occupy social professional positions that are characteristic for it, the middle class should be characterized by the presence of human capital that is able to generate an income. In order to measure this characteristic, the level of education with a threshold value "presence of basic higher education" is used. This allows selecting those who have relatively advanced professional skills, consequently have a corresponding specific capital. Thus, the level of education is a marker for a certain professional level and allows selecting the groups that could occupy structural positions that allows generating income on their human capital. Two higher education and all other degrees clearly indicate the individual's belonging to the middle class.

- Level of self - identification (self-evaluation by the individual of position in society should be not lower than "middle class" in the proposed structure). Finally, the last criterion which is used to allocate 
the middle class is self-identification. It should be noted that the awareness of themselves as a class, is not a vitally important condition for the existence of class. This criterion is important, since the middle class is not only a social stratification concept, but also a value category. At the forefront of its features certain traits of character, behavior are put forward which people belonging to this class should have [3]. This approach uses an individual self-evaluation of its position in society, which should be not lower than the "middle class". This allows weeding out of the analysis those who feel as social outsiders, therefore obviously will not fit on the specifics of consciousness and behavior of the middle class.

In general, summing this approach of research, it can be said that it is based on a broader definition of the middle class. In this case, middle class include those whose needs appear above basic human needs such as food and clothing, and at the same time have the necessary resources and the intention to raise the standard of living due to skillful use of their knowledge and skills. Thus, the middle class differs from other social groups by significant volume of concentrated tangible assets, social and cultural, such concentration of wealth, professional experience, social status, style of consumption, suggests it as a leading part of the society.

Material situation: The share of middle class in the total population is large enough. However, it should be considered that, like any social group, highlighted middle class is not homogeneous. Firstly, there can be allocated a first middle layer (so-called core) that combines the typical representatives of the group, which is most clearly express its characteristics and which is relatively stable but numerically small compared to other social formations. Then, the second middle layer that is a structural reserve for the first middle layer; the lower middle layer in which the attributes characteristic for the middle class, gradually weakens. Also the top layer of the middle class, lower class and layer of "status mismatches" are allocated.

The upper layer of the middle class $(1.2 \%)$ includes respondents that have a stable steady income, as well as the average per capita income of more than 100 thousand KZT which is more than 5.3 living wages, have at least basic higher education, with non-physical nature of work, indicating their affiliation in a given structure as - the highest social class. $83.3 \%$ of respondents rated their financial status in the hierarchy of income as "stable", they do not have any financial difficulties, if desired, can afford to buy an apartment or a house.
The first middle layer (5.2\%) - this layer includes respondents who also have all four criteria defining the middle class, namely the existence of a stable permanent income, presence of higher education (minimum basic higher), non-physical nature of work, with self-identification in the proposed scale "higher middle" or "middle".

The second middle layer (transitional layer $40.6 \%$ ) is composed of people close to the core of the middle class. Representatives of this layer have an average monthly per capita income from 55 to 100 thousand KZT, and have indirect well-being criteria close to the middle class. These are people who form reserve of the middle-class core, and have the potential to become part of a middle class core in the future. It is necessary to consider the fact that this layer is heterogeneous. Thus, the structural reserve is formed of subgroups in which the properties and criteria of the middle class is gradually attenuated.

Lower middle layer (34.4\%) given layer includes respondents having a per capita income of 35 to 55 thousand KZT, which is about 2 to 3 living wages also having other indirect signs of well-being. This layer is also very heterogeneous and numerous. Therefore, this layer is also divided into several subgroups as characteristic signs of the middle class are weakened (Fig.1).

Lower class $(15.9 \%)$ includes respondents with an average monthly income below the 2 living wages (to 35 thousand KZT) per family member. Also, when analyzing the data, controversial layer "group of status mismatches" was defined: people with high incomes that are inconsistent with level of education and occupation $-2.7 \%$.

Talking about the differences of Kazakh middle class from the Western countries, experts agree that today comparing Kazakhstan and countries of Western Europe and the United States does not make sense, as well as searching of differences between middle classes in these countries as they are at different stages of their development, having their own specificity in mentality, consumer characteristics and economic realities.

Expert 5 (civil servant): Firstly, based on our economic realities there is still very long way for the middle class in Kazakhstan to the middle class of Western Europe, and the United States. In our view, based on the realities, in each state should be its own criteria of the identification of middle class. Second, if the middle class of developed countries was established, and a significant part of it compose small and medium business, workers of factories, the vast majority of doctors and teachers, the Kazakh middle class is in the process of formation, 
as doctors and teachers, workers of factories and etc., unfortunately, today cannot be classified as a middle class.

Expert 1 (sociologist-practitioner): Firstly, it is very difficult to talk about the Western middle class; the middle class has its own national characteristics in each country. .... The mentality is different, the differences in the economic, consumer features, moral values. Differences between Western middle class and our middle class are shrinking but the main difference is the ratio of the individual, respect for the rights and dignity of the individual... In the West, one is aware of its duty, its responsibilities.... Our middle class cannot solve problems in a civilized way, through the courts, through the structures of civil society.....

As can be seen from the Table 1, 12.2\% of respondents indicate that the average per capita income in their family is between 85 and 100 thousand KZT, $9.5 \%$ of respondents said that their average per capita income over the past 6 months ranged from 7 to 20 thousand KZT. Slightly less $9.1 \%$ indicated that their income per family member - more than 100 thousand KZT. Given the high percentage of respondents found it difficult to answer this question, special attention was paid to indirect signs of well-being.

Self-evaluation of material situation (Table 2) shows that overall $24.5 \%$ of the respondents can buy basic appliances, but have trouble buying more expensive items such as a car; slightly more $30.7 \%$ say that only such acquisitions as an apartment or vacation home are difficult for them. In the upper layer of the middle class $83.3 \%$ of respondents said that they have no financial difficulties at all. In the core of the middle class respondents' opinions are fairly evenly distributed.

In the second middle layer present all the options of self-evaluation. There are respondents that have enough money for food and clothing, but buying a TV is difficult, the amount of such people increases in the distant periphery and among rest of the population. Majority of respondents indicated that they experience difficulties in buying more expensive items (car - 23.9\%, apartment or house - $40.6 \%$ ), while $16.8 \%$ of respondents said that they have no financial difficulties.

In the lower middle layer increases the number of respondents who indicate that buying large home appliances is difficult for them - $14.4 \%$. At the same time, $27.5 \%$ of this layer believes that their funds are enough for large home appliances, while purchasing a car is difficult for them. $22.1 \%$ of respondents of the distant periphery also note that their funds are sufficient for everything, but expensive acquisitions as an apartment or vacation home.

Interest in the political life of the country: Interest in political life in Kazakhstan, as well as an active expression of their civil position in relation to the different situations occurring in the country, is one of the main signs that show the maturity of the middle class. It is characterized by its own ideology, which is based on the understanding of group interests and their role in society. On the one hand, it does not want a repetition of historical events, the lack of stability and confidence in the future and tranquility for their own well-being. Thus forms the need for moderate conservatism related to the conservation of traditions and strong government. Conservatism is intended to help preserve the current level and further growth of consumption. On the other hand, the middle class feels the need for presence of conditions for the implementation of its initiatives, life plans and ambitions [4].

According to a study in the upper middle layer $66.7 \%$ of respondents are always interested in politics. The vast majority of the representatives of the first middle layer are interested political life of the country only from time to time. In the second middle layer majority (58.4\%) occasionally shows interest in political life and the political situation in Kazakhstan, $26.9 \%$ of respondents are constantly interested in it. $53.3 \%$ of lower middle layer interests from time to time, while $25.1 \%$ are not interested at all. Percentage of respondents who not interested in the political life of the country at all increases linearly from the upper layer to the lower class from $0 \%$ to $27.3 \%$.

In the lowest class $40.2 \%$ of the respondents are occasionally interested in political life in Kazakhstan, in this class the largest percentage of respondents who are not interested in political events in the country at all, although the percentage of those who are constantly interested in political life is big enough $32,5 \%$.

As data shows, an active civic position in the upper middle layer is expressed by $66.7 \%$ of respondents. For comparison, only $37.7 \%$ of respondents of lower class actively express their civic position, $22.1 \%$ of respondents do not express their position at all and $14.3 \%$ of respondents do not tend to express their civic position. In the layer of status mismatches opinions were divided almost evenly $53.8 \%$ of respondents in one way or another express their civic position, $46.2 \%$ of respondents practically does not express it.

Number of respondents who actively express their civic position, linearly decreases in the second 
middle layer. In the lower middle layer of the number of people in varying degrees not expressing their civic position actively increases in those subgroups, which by weakening signs of middle class tend to the lower class.

Therefore, even though interest in the political life in Kazakhstan is mainly manifested from time to time, and decreases as the signs of the middle class weakens, in one way or another, most of these two layers actively express their civic position, regardless of the present criteria defining middle class.

For the question whether you are ready to leave Kazakhstan opinions of the lower class representatives are distributed almost evenly: $44.2 \%$ who are ready to leave Kazakhstan, and $48.1 \%$ of the respondents who did not consider such option for the future. The situation is similar in the layer of status mismatches, while $53.8 \%$ did not consider the option of moving to another country as a permanent place of residence, $46.2 \%$ are ready to leave Kazakhstan. While in all layers of the middle class the vast majority of respondents note their unwillingness to leave Kazakhstan.

Conclusion: In general, summing this approach of research, it can be said that it is based on a broader definition of the middle class. In this case, middle class include those whose needs appear above basic human needs such as food and clothing, and at the same time have the necessary resources and the intention to raise the standard of living due to skilful use of their knowledge and skills. Thus, the middle class differs from other social groups by significant volume of concentrated tangible assets, social and cultural, such concentration of wealth, professional experience, social status, style of consumption, suggests it as a leading part of the society.

Kazakhstan's middle class today is heterogeneous and consists of several layers (upper, first middle layer, second middle layer, lower middle layer). In turn, upper middle layer and first middle layer have all the features of the middle class in its classical meaning. While the second middle layer and lower middle layer are the most numerous and extremely heterogeneous in composition, thereby break down into several subgroups as middle class signs weaken.

As the results of the research show, the system of values of the middle class as a complete structure has not yet been formed, and is only in the initial stage. It should be noted that the values of the lower and middle class do not differ from each other, although the trends to change can be seen. Hence, such a model of values diffusion is an evidence of the ongoing process of formation of group consciousness and values. It should be noted also that these data demonstrate the mechanism of diffusion of new values, which comes from the upper middle layer and the first middle layer, gradually weakening. And this explains the fact of heterogeneous spread of values, attitudes, lifestyles in different layers of the middle class.

\section{References}

1 Institute of Sociology of the Russian Academy of Sciences (2006). Urban middle class in modern Russia. Available: http://www.isras.ru/analytical_report_MiddleClass_1.html?\&printmode (February 14, 2016).

2 Burkhanova D.K. Features of determination of middle class in Kazakhstan, International forum of young scientists of CIS "Youth in sciencse-2012", Kazakhstan, 2012, pp.32-35.

3 Diligenskiy G.G. Ludi srednego klassa [People of the middle class]. Moscow: Institute of "Public opinion, 2002.

4 Bosc S. Sociologie des classes moyennes, Paris: La Découverte, 2008, 128p.

5 Goux D., Maurin E. Les nouvelles classes moyennes, Paris: ed. du Seuil et la République des idées, 2012, 121 p. 